\title{
Second primary malignancies after ocular adnexal lymphoma diagnosis
}

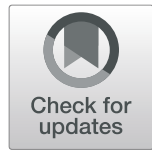

Asad Loya', Vignesh Ramachandran', Talha Ayaz ${ }^{2}$ and Christina Y. Weng ${ }^{3^{*}}$

\begin{abstract}
Background: Although studies have investigated the risk of second primary malignancies (SPMs) associated with lymphoma of various sites, limited studies have investigated this risk in patients with lymphoma originating within the ocular adnexa. We conducted a retrospective study to assess incidence of secondary malignancies in patients with a prior diagnosis of ocular adnexal lymphoma (OAL) and to determine latency periods and age-groups at increased risk for SPM occurrence.

Methods: Retrospective analysis was performed on data obtained from Surveillance, Epidemiology, and End Results (SEER) 9 database. Patients with an initial primary malignancy diagnosis of OAL between 1973 and 2015 were included in the study. Standardized incidence ratios (SIR) and excess absolute risks (EAR) compared to a SEER reference population with similar sex, race, age, and calendar year were computed for SPMs. Excess absolute risk is per 10,000 individuals; alpha of 0.05 was used.

Results: Of 1834 patients with primary ocular adnexal lymphoma, 279 developed a secondary malignancy during average follow-up of 110.03 months (+/-88.46), denoting higher incidence than expected (SIR 1.20; 95\% Cl, 1.07 to 1.35; EAR 30.56). Amongst the primary lymphoma cohort, $98.7 \%$ (1810/1834) of patients had non-Hodgkin's lymphoma and amongst those that developed secondary malignancies, 99.6\% (278/279) had non-Hodgkin's lymphoma. Patients exhibited increased incidence of lymphohematopoietic and non-lymphohematopoietic second malignancies and no secondary malignancies of the eye or orbit. Patients had increased incidence of secondary malignancies in the first year (SIR 2.07; 95\% Cl, 1.49 to 2.79; EAR 150.37) and 1-5 years following lymphoma diagnosis (SIR 1.24; 95\% Cl, 1.01 to 1.51; EAR 34.89). Patients with various OAL subtypes demonstrated differing patterns of site-specific and overall SPM risk.

Conclusions: Patients with prior diagnosis of ocular adnexal lymphoma possess increased risk of hematologic and non-hematologic secondary malignancies. Risk of secondary malignancy could vary by lymphoma subtype. Patients with ocular adnexal lymphoma may benefit from regular surveillance to promote early detection of second primary malignancies.
\end{abstract}

Keywords: OAL, ocular, adnexa, lymphoma, second, primary, malignancy, cancer, neoplasm, NHL

\footnotetext{
* Correspondence: christina.weng@bcm.edu

${ }^{3}$ Baylor College of Medicine, Department of Ophthalmology-Cullen Eye

Institute, 1977 Butler Boulevard, Houston, TX 77030, USA

Full list of author information is available at the end of the article
}

(c) The Author(s). 2021 Open Access This article is licensed under a Creative Commons Attribution 4.0 International License, which permits use, sharing, adaptation, distribution and reproduction in any medium or format, as long as you give appropriate credit to the original author(s) and the source, provide a link to the Creative Commons licence, and indicate if changes were made. The images or other third party material in this article are included in the article's Creative Commons licence, unless indicated otherwise in a credit line to the material. If material is not included in the article's Creative Commons licence and your intended use is not permitted by statutory regulation or exceeds the permitted use, you will need to obtain permission directly from the copyright holder. To view a copy of this licence, visit http://creativecommons.org/licenses/by/4.0/. The Creative Commons Public Domain Dedication waiver (http://creativecommons.org/publicdomain/zero/1.0/) applies to the data made available in this article, unless otherwise stated in a credit line to the data. 


\section{Background}

First described in 1952, ocular adnexal lymphoma (OAL), a subset of orbital lymphoproliferative disorders, is the most common malignancy involving the ocular adnexa and comprises $11-24 \%$ of all ocular tumors [1, 2]. OAL can originate from the orbit and surrounding structures, including the conjunctiva, orbital soft tissues, eyelid, lacrimal glands/drainage system or other adnexa [3]. These neoplasms are broadly classified as Hodgkin's lymphoma (HL) and non-Hodgkin's lymphoma (NHL), although NHL accounts for the vast majority of OAL. NHL is comprised of neoplasms derived from clonal proliferation of $\mathrm{B}$ or $\mathrm{T}$ lymphocytes of nodal or extranodal sites [4]. Most OALs are classified as low-grade Bcell NHL, and while most NHL arise from mature B lymphocytes (80\%), T (14\%), NK (6\%), and plasma cell lines have also been implicated [5]. The most common major lymphoma subtypes responsible for OAL are extranodal marginal-zone B-cell lymphoma (EMZL) (55-66\%), follicular lymphoma (FL) (10-29\%), diffuse large B-cell lymphoma (DLBCL) (9-13\%), mantle cell lymphoma (MCL) (6-11\%), and small lymphocytic lymphoma (CLL/SLL) $(2-5 \%)[6,7]$.

Improvements in screening, early detection, palliative care, and definitive therapy have tripled the number of cancer survivors in the United States since 1971, and that number continues to grow at a rate of $2 \%$ annually [8]. Therefore, quantification of cancer sequelae and longterm effects of treatment, including second primary malignancy (SPM), has become increasingly important. OAL generally has favorable survival with a 5 -year survival rate of 50-94\%; however, many of these patients receive radiation, chemotherapy, or immunomodulation, which can increase susceptibility for SPMs [9, 10]. Patients with SPMs have worse survival compared to patients with isolated primary malignancies and may also suffer from sequelae such as vision loss and disfigurement [11, 12]. While the Surveillance, Epidemiology, and End Results (SEER) Program has been used to investigate SPMs in patients with other primary ophthalmic malignancies, [13, 14] little is understood about the risk of SPMs in patients with primary OAL.

In this study, the authors present a population-based study utilizing the SEER database to assess whether patients with primary OAL exhibit an increased incidence of SPMs compared to the general population. In doing so, the authors aim to assess types of SPMs that patients with history of OAL develop and to evaluate latency periods and age groups at particular risk for development of these SPMs.

\section{Methods}

\section{Data extraction}

Data was obtained from National Cancer Institute's (NCI) SEER cancer registry database using Seer*stat (version 8.3.5) [15]. The database contains 18 registries, accounting for approximately $28 \%$ of the United States population. The dataset with 18 registries is limited to cases diagnosed after 2000, for which reason this study utilized the 9 registries dataset "SEER 9 Regs Research Data, Nov 2017 Sub (1973-2015)," containing cases diagnosed from 1973 to 2015 . The database includes data related to patient demographics, tumor characteristics, treatment, and survival; it however lacks data related to modifiable risk factors (e.g., obesity, smoking), comorbidities, and specific treatment data (e.g., radiation dose, chemotherapy regimen). As only deidentified data was analyzed with permission from NCI, no institutional review board approval was required for this study in accordance with institutional policy.

\section{Data collection}

All cases reporting a first primary tumor of OAL between 1973 and 2015 were included in the study. OAL was classified using the Collaborative Staging schema's (v2.04) definition. Cases diagnosed at autopsy or by death certificate were excluded from the study. Only malignancies diagnosed 2 or more months after the first primary OAL diagnosis were considered as SPMs, in order to distinguish true secondary malignancies from multicentric lymphomas or concurrently diagnosed malignancies due to screening. Demographic variables collected included age group, race, and gender. Tumor characteristics collected include primary site, laterality, and histology. Vital status at end of follow-up period and surgical intervention were also documented.

\section{Statistical analysis}

SPM analysis was conducted through a multiple primary standardized incidence ratio (MP-SIR) session using the Seer*stat program. Standardized incidence ratios (SIR) with 95\% confidence intervals (95\% CI) and excess absolute risks (EAR) compared to those in the general population with similar sex, race (white/unknown, black, other), age group (5-year interval), and calendar year (5-year interval) were computed for SPMs after OAL. Subanalysis was performed using the same algorithm to compute SPMs after 5 specific OAL subtypes: EMZL, FL, DLBCL, MCL, CLL/SLL. The reference population used for the study was "SEER 9 1973-2015 (Nov 2017 sub), Race (WU/B/O), Event: Site recode B ICD-O-3/WHO 2008," and is composed of Census Bureau data provided by SEER, in partnership with National Center for Health Statistics (https://seer.cancer.gov/popdata/). EAR was calculated per 10,000 individuals and a significance level of 0.05 was used. Descriptive analysis was conducted using IBM Statistical Package for the Social Sciences Statistics version 25 . 


\section{Results}

\section{Cohort characteristics}

Of 1834 patients with first primary OAL, 279 individuals developed a SPM during an average follow-up period of 110.03 months (+/-88.46). Demographic, tumor, treatment, and survival information are displayed in Table 1. Orbit (not otherwise specified [NOS]) was the most common site of OAL within both the overall cohort (50.9\%; 933/1834) and the SPM subset of the overall cohort $(47.3 \% ; 132 / 279)$. Majority of patients were managed without surgical intervention in the overall cohort $(57.1 \% ; 1047 / 1834)$, as well as in the SPM subcohort (58.4\%; 163/279). Similarly, majority of patients received radiation therapy in both the overall cohort (64.3\%; $1179 / 1834$ ) and SPM subcohort (62.0\%; 173/279). In contrast, chemotherapy was received by minority of patients in both the overall cohort $(21.5 \%$; 394/1834) and SPM subcohort $(21.1 \% ; 59 / 279)$. At the end of the follow-up period, $54.4 \%$ (998/1834) of patients from the overall cohort survived and $36.8 \%(101 / 279)$ of patients from the SPM subcohort survived.

NHL was the predominant lymphoma sub-type amongst both the overall cohort $(98.7 \% ; 1810 / 1834)$ and SPM subcohort $(99.6 \% ; 278 / 279)$. The overall cohort was composed of $37.8 \%$ (693/1834) EMZL, 11.2\% (206/ 1834) FL, 10.5\% (192/1834) DLBCL, 10.0\% (184/1834) CLL/SLL, and 3.8\% (69/1834) MCL. The SPM subcohort was composed of $26.9 \%(75 / 279)$ EMZL, 14.7\% (41/279) FL, 10\% (28/279) DLBCL, 18.6\% (52/279) CLL/SLL, and $4.3 \%(12 / 279)$ MCL. Majority of remainder cases in both the overall cohort and SPM subcohort were either not otherwise specified or of unknown lineage.

Table 1 Demographic and tumor characteristics of patients at time of OAL diagnosis and survival status at end of follow-up period

\begin{tabular}{|c|c|c|c|c|c|}
\hline & & \multicolumn{2}{|c|}{ Overall Cohort } & \multicolumn{2}{|c|}{ SPM Cohort } \\
\hline & & $\mathrm{n}$ & $\%$ & $\mathrm{n}$ & $\%$ \\
\hline \multirow[t]{3}{*}{ Age Group } & $0-49$ & 373 & 20.3 & 30 & 10.8 \\
\hline & $50-69$ & 769 & 41.9 & 145 & 52 \\
\hline & $70+$ & 692 & 37.7 & 104 & 37.3 \\
\hline \multirow[t]{3}{*}{ Race } & White/Unknown & 1504 & 82 & 233 & 83.5 \\
\hline & Black & 143 & 7.8 & 17 & 6.1 \\
\hline & Other & 187 & 10.2 & 29 & 10.4 \\
\hline \multirow[t]{2}{*}{ Gender } & Female & 1015 & 55.3 & 141 & 50.5 \\
\hline & Male & 819 & 44.7 & 138 & 49.5 \\
\hline \multirow[t]{4}{*}{ Primary site } & Conjunctiva & 522 & 28.5 & 84 & 30.1 \\
\hline & Lacrimal Gland & 220 & 12 & 37 & 13.3 \\
\hline & Orbit, NOS & 933 & 50.9 & 132 & 47.3 \\
\hline & Eyelid & 159 & 8.7 & 26 & 9.3 \\
\hline \multirow[t]{3}{*}{ Laterality } & Unilateral & 1693 & 92.3 & 260 & 93.2 \\
\hline & Bilateral & 119 & 6.5 & 15 & 5.4 \\
\hline & Unknown/NA & 22 & 1.2 & 4 & 1.4 \\
\hline \multirow[t]{3}{*}{ Surgery status } & Performed & 763 & 41.6 & 110 & 39.4 \\
\hline & Not Performed & 1047 & 57.1 & 163 & 58.4 \\
\hline & Unknown & 24 & 1.3 & 6 & 2.2 \\
\hline \multirow[t]{2}{*}{ Chemotherapy Status } & Received & 394 & 21.5 & 59 & 21.1 \\
\hline & Not Received/Unknown & 1440 & 78.5 & 220 & 78.9 \\
\hline \multirow[t]{2}{*}{ Radiation status } & Received & 1179 & 64.3 & 173 & 62 \\
\hline & Not Received/ Unknown & 655 & 35.7 & 106 & 38 \\
\hline \multirow[t]{2}{*}{ Vital status } & Living & 998 & 54.4 & 101 & 36.2 \\
\hline & Deceased & 836 & 45.6 & 178 & 63.8 \\
\hline \multirow[t]{3}{*}{ Type of cancer } & Hodgkin's - Extranodal & 2 & 0.1 & 0 & 0 \\
\hline & Plasmacytoma & 22 & 1.2 & 1 & 0.4 \\
\hline & Non-Hodgkin's - Extranodal & 1810 & 98.7 & 278 & 99.6 \\
\hline
\end{tabular}




\section{SPM incidence}

The incidence of malignancies was higher than that of the general population (SIR 1.20; 95\% CI, 1.07 to 1.35; EAR 30.56). This can be attributed to increased occurrences of both hematologic and non-hematologic malignancies; SPMs of lymphohematopoietic origin included Hodgkin's lymphoma (SIR 5.64; 95\% CI, 1.16 to 16.47; EAR 1.6), non-Hodgkin's lymphoma (SIR 5.29; 95\% CI, 3.95 to 6.93; EAR 27.27), and leukemia (SIR 2.20; $95 \%$ CI, 1.23 to 3.62 ; EAR 5.28) whereas SPMs of nonlymphohematopoietic origin included non-epithelial skin sites (excluding melanoma and keratinocytic neoplasms; i.e. Merkel cell carcinoma, sebaceous adenocarcinoma, sweat gland adenocarcinoma) (SIR 4.91; 95\% CI, 1.59 to 11.46; EAR 2.58), the kidney (SIR 2.08; 95\% CI, 1.08 to 3.64; EAR 4.03), and the nervous system excluding brain (SIR 19.90; 95\% CI, 2.41 to 71.89; EAR 1.23) (Table 2). Notably, there was a decreased incidence of female breast cancer (SIR 0.62; 95\% CI, 0.37 to 0.97; EAR $7.51)$. Additionally, no SPMs occurred in the eye or orbit (SIR 0; 95\% CI, 0 to 10.64; EAR -0.22).

\section{SPM age and latency analysis}

Patients with history of OAL demonstrated increased incidence of overall secondary malignancies within the first year (2-11 months) of OAL diagnosis (SIR 2.07; 95\% CI, 1.49 to 2.79; EAR 150.37) and $1-5$ years following OAL diagnosis (SIR 1.24; 95\% CI, 1.01 to 1.51 ; EAR 34.89). Patients with age $0-49$ years (SIR 2.41; 95\% CI, 1.25 to 4.22; EAR 28.77) and 50-69 years (SIR 1.33; $95 \%$ CI, 1.08 to 1.62 ; EAR 38.98 ) had increased overall incidence of SPMs. In contrast, patients greater than 70 years (SIR 1.10; 95\% CI, 0.94 to 1.28; EAR 23.15) demonstrated no difference.

Age groups with increased susceptibility to SPMs differed by malignancy origin (Table 3 ). Increased incidence of secondary NHL was found in the $0-49$ years (SIR 8.34; 95\% CI, 1.01 to 30.14; EAR 7.21), 50-69 years (SIR 8.44; 95\% CI, 5.35 to 12.67; EAR 31.85), and greater than 70 years (SIR 3.93; 95\% CI, 2.59 to 5.72; EAR 30.25) subgroups. On the other hand, increased incidence for SPMs of the kidney was found in the 0-49 years subgroup (SIR 12.77; 95\% CI, 1.55 to 46.12; EAR 7.55), for non-epithelial skin in the 50-69 years subgroup (SIR 10.20; $95 \%$ CI, 1.23 to 36.83; EAR 2.83), for HL in the 50-69 years subgroup (SIR 10.93; 95\% CI, 1.32 to 39.49; EAR 3.85), and for leukemia in the greater than 70 years subgroup (SIR 2.58; 95\% CI, 1.38 to 4.42; EAR 11.98). Secondary malignancies of the nervous system (excluding brain) did not demonstrate a significant difference in incidence in any particular age group.

Similarly, latency periods with increased risk for secondary malignancies differed by origin (Table 4). Leukemia and SPMs originating in the kidney (SIR 8.31;
95\% CI, 2.26 to 21.27) and nervous system (SIR 109.46; 95\% CI, 2.77 to 609.86) demonstrated increased incidence within a year (2-11 months) of OAL diagnosis. NHL demonstrated increased incidence $1-5$ years (SIR 5.85; 95\% CI, 3.52 to 9.14 ), 5-10 years (SIR 2.93; 95\% CI, 1.27 to 5.78 ), and $10+$ years (SIR $7.24 ; 95 \% \mathrm{CI}, 4.53$ to 10.95) from OAL diagnosis. HL displayed increased incidence 5-10 years (SIR 13.60; 95\% CI, 1.65 to 49.11) from OAL diagnosis. SPMs of the skin did not demonstrate any significant patterns regarding latency.

\section{Sub-analysis by OAL subtype}

SPM incidence further varied by OAL subtype (Table 5). Patients with initial FL (SIR 1.48; 95\% CI, 1.06 to 2.01; EAR 79.48) and CLL/SLL (SIR 1.52; 95\% CI, 1.13 to 1.99; EAR 84.31) were found to have increased incidence of malignancies relative to the general population, whereas patients with EZML (SIR 1.13; 95\% CI, 0.89 to 1.41; EAR 17.23), DLBCL (SIR 1.38; 95\% CI, 0.92 to 1.99; EAR 60.99), and MCL (SIR 1.20; 95\% CI, 0.62 to 2.09; EAR 33.87) were found to have no difference in incidence of malignancies. Patients with prior FL or CLL/SLL demonstrated increased incidence of both hematologic and solid malignancies. Patients with prior EZML demonstrated increased incidence of hematologic but not solid malignancies, whereas those with prior DLBCL demonstrated increased incidence of solid but not hematologic malignancies. Conversely, patients with prior MCL were found to have no difference in incidence of either solid or hematologic malignancies relative to the general population.

\section{Discussion}

Using a population-based cancer database, we conducted a retrospective analysis of 1834 patients with OAL and found an increased incidence of overall SPMs compared to the general population, mostly within the first 5 years of OAL diagnosis and in individuals up to 70 years of age. Compared to the general population, patients with prior OAL diagnosis are at increased risk for lymphohematopoietic secondary malignancies such as HL, NHL, leukemia, and SPMs of solid sites such as in the kidney, non-epithelial skin (excluding melanoma and keratinocytic neoplasms), and nervous system (excluding brain).

While there is vast literature on occurrence of SPMs in patients with prior lymphoma, sparse data exists regarding SPMs in patients with prior lymphoma specific to the ocular adnexa. In this study, the majority (99.6\%) of cases were characterized histologically as NHL. Chattopadhyay, et al. and Chien, et al. examined SPMs following NHL of non-specified sites and, similar to us, found an overall increased incidence of developing SPMs. Moreover, these authors found an increased incidence of SPMs at sites similar to those in our study, 
Table 2 Site-specific standardized incidence ratios and excess absolute risks of SPMs in patients with previous OAL

\begin{tabular}{|c|c|c|c|c|}
\hline Second Cancer Site & 0 & O/E & $95 \% \mathrm{Cl}$ & $\mathrm{EAR}^{* *}$ \\
\hline All Sites & 279 & $1.20^{*}$ & $1.07-1.35$ & 30.56 \\
\hline All Sites excluding Non-Melanoma Skin & 274 & $1.19^{*}$ & $1.05-1.34$ & 27.98 \\
\hline All Solid Tumors & 193 & 0.94 & $0.82-1.09$ & -7.46 \\
\hline Oral Cavity and Pharynx & 2 & 0.39 & $0.05-1.42$ & -1.99 \\
\hline Digestive System & 48 & 0.99 & $0.73-1.31$ & -0.3 \\
\hline Respiratory System & 35 & 0.96 & $0.67-1.33$ & -1.01 \\
\hline Bones and Joints & 1 & 4.8 & $0.12-26.73$ & 0.51 \\
\hline Soft Tissue including Heart & 1 & 0.84 & $0.02-4.68$ & -0.12 \\
\hline Skin excluding Basal and Squamous & 11 & 1.17 & $0.58-2.09$ & 1.01 \\
\hline Melanoma of the Skin & 6 & 0.71 & $0.26-1.55$ & -1.56 \\
\hline Other Non-Epithelial Skin & 5 & $4.91^{*}$ & $1.59-11.46$ & 2.58 \\
\hline Breast & 19 & $0.62^{*}$ & $0.37-0.96$ & -7.68 \\
\hline Female Breast & 19 & $0.62^{*}$ & $0.37-0.97$ & -13.29 \\
\hline Male Breast & 0 & 0 & $0-14.22$ & -0.39 \\
\hline Female Genital System & 12 & 0.99 & $0.51-1.73$ & -0.16 \\
\hline Male Genital System & 38 & 1.07 & $0.75-1.46$ & 3.51 \\
\hline Urinary System & 24 & 1.22 & $0.78-1.81$ & 2.75 \\
\hline Urinary Bladder & 12 & 0.94 & $0.48-1.64$ & -0.52 \\
\hline Kidney and Renal Pelvis & 12 & 1.89 & $0.98-3.3$ & 3.65 \\
\hline Renal Pelvis, Ureter, and Other Urinary Organs & 0 & 0 & $0-3.12$ & -0.77 \\
\hline Kidney & 12 & $2.08^{*}$ & $1.08-3.64$ & 4.03 \\
\hline Renal Pelvis & 0 & 0 & $0-6.24$ & -0.38 \\
\hline Ureter & 0 & 0 & $0-9.7$ & -0.25 \\
\hline Other Urinary Organs & 0 & 0 & $0-17.37$ & -0.14 \\
\hline Eye and Orbit & 0 & 0 & $0-10.64$ & -0.22 \\
\hline Brain and Other Nervous System & 2 & 0.87 & $0.11-3.15$ & -0.19 \\
\hline Brain & 0 & 0 & $0-1.68$ & -1.42 \\
\hline Cranial Nerves/Other Nervous System & 2 & $19.90^{*}$ & $2.41-71.89$ & 1.23 \\
\hline Endocrine System & 5 & 1.81 & $0.59-4.22$ & 1.45 \\
\hline All Lymphatic and Hematopoietic Diseases & 75 & $3.64^{*}$ & $2.86-4.56$ & 35.17 \\
\hline Lymphoma & 55 & $5.30^{*}$ & $4-6.9$ & 28.87 \\
\hline Hodgkin's & 3 & $5.64^{*}$ & $1.16-16.47$ & 1.6 \\
\hline HL - Nodal & 3 & $5.86^{*}$ & $1.21-17.13$ & 1.61 \\
\hline $\mathrm{HL}$ - Extranodal & 0 & 0 & $0-180.57$ & -0.01 \\
\hline Non-Hodgkin's & 52 & $5.29^{*}$ & $3.95-6.93$ & 27.27 \\
\hline NHL - Nodal & 23 & $3.51^{*}$ & $2.22-5.26$ & 10.63 \\
\hline $\mathrm{NHL}$ - Extranodal & 29 & $8.84^{*}$ & $5.92-12.7$ & 16.64 \\
\hline Myeloma & 5 & 1.46 & $0.48-3.42$ & 1.02 \\
\hline Leukemia & 15 & $2.20^{*}$ & $1.23-3.62$ & 5.28 \\
\hline Lymphocytic Leukemia & 6 & 1.76 & $0.65-3.83$ & 1.67 \\
\hline Acute Lymphocytic Leukemia & 0 & 0 & $0-19.88$ & -0.12 \\
\hline Chronic Lymphocytic Leukemia & 6 & 1.98 & $0.73-4.32$ & 1.92 \\
\hline Other Lymphocytic Leukemia & 0 & 0 & $0-18.31$ & -0.13 \\
\hline Non-Lymphocytic Leukemia & 9 & $2.63^{*}$ & $1.2-5$ & 3.61 \\
\hline
\end{tabular}


Table 2 Site-specific standardized incidence ratios and excess absolute risks of SPMs in patients with previous OAL (Continued)

\begin{tabular}{|c|c|c|c|c|}
\hline Second Cancer Site & 0 & O/E & $95 \% \mathrm{Cl}$ & $\mathrm{EAR}^{* *}$ \\
\hline Acute Non-Lymphocytic Leukemia (ANLL) & 7 & $3.17^{*}$ & $1.28-6.54$ & 3.1 \\
\hline Myeloid and Monocytic Leukemia & 9 & $3.03^{*}$ & $1.39-5.75$ & 3.9 \\
\hline Acute Myeloid Leukemia & 6 & $3.17^{*}$ & $1.16-6.91$ & 2.66 \\
\hline Acute Monocytic Leukemia & 1 & 9.62 & $0.24-53.57$ & 0.58 \\
\hline Chronic Myeloid Leukemia & 1 & 1.14 & $0.03-6.38$ & 0.08 \\
\hline Other Myeloid/Monocytic Leukemia & 1 & 9.96 & $0.25-55.5$ & 0.58 \\
\hline Other Leukemia & 0 & 0 & $0-8.18$ & -0.29 \\
\hline Other Acute Leukemia & 0 & 0 & $0-17.57$ & -0.14 \\
\hline Aleukemic, Subleukemic and NOS & 0 & 0 & $0-15.29$ & -0.16 \\
\hline Mesothelioma & 0 & 0 & $0-5.98$ & -0.4 \\
\hline Kaposi Sarcoma & 0 & 0 & 0-19.49 & -0.12 \\
\hline Miscellaneous & 6 & 1.07 & $0.39-2.34$ & 0.27 \\
\hline
\end{tabular}

Cl Confidence interval; $E$ Expected; HL Hodgkin's lymphoma; NHL Non-Hodgkin's lymphoma; O Observed; OAL Ocular adnexal lymphoma; SIR Standardized incidence ratio; SPM Second primary malignancy. ${ }^{* *}$ Per 10,000 individuals. ${ }^{*} P<0.05$

including kidney, skin, lymphoreticular system, and central nervous system $[16,17]$.

An increase in SPMs of the lymphoreticular system is likely attributable to shared pathophysiology between primary and secondary malignancies. Increased incidence of NHL was found after 1 year from primary OAL diagnosis. Specific OAL subtypes demonstrating this finding were EZML, FL, and CLL/SLL. As the majority of OAL cases in this study were NHL, this finding is more likely representative of local/regional/distant recurrence than true SPM occurrence, a distinction which is not well-defined in the SEER database; the database

Table 3 Standardized incidence ratios and excess absolute risks of secondary malignancy distributed by time from diagnosis of the primary OAL

\begin{tabular}{|c|c|c|c|c|c|c|c|c|}
\hline \multirow[t]{3}{*}{ Cancer Site } & \multicolumn{8}{|c|}{ Time Since Diagnosis } \\
\hline & \multicolumn{2}{|r|}{ 2-11 months } & \multicolumn{2}{|r|}{ 12-59 months } & \multicolumn{2}{|r|}{$60-119$ months } & \multicolumn{2}{|r|}{$120+$ months } \\
\hline & 0 & O/E (95\% Cl) & 0 & O/E (95\% Cl) & 0 & O/E (95\% Cl) & 0 & O/E (95\% Cl) \\
\hline All Sites & 42 & $2.07^{*}(1.49-2.79)$ & 98 & $1.24^{*}(1.01-1.51)$ & 57 & $0.89(0.68-1.16)$ & 82 & $1.2(0.95-1.48)$ \\
\hline Other Non-Epithelial Skin & 1 & $12.86(0.33-71.66)$ & 1 & $3.16(0.08-17.6)$ & 1 & $3.53(0.09-19.69)$ & 2 & $5.87(0.71-21.2)$ \\
\hline Female Breast & 3 & $1.12(0.23-3.27)$ & 4 & $0.38^{*}(0.1-0.98)$ & 2 & $0.23 *(0.03-0.83)$ & 10 & $1.15(0.55-2.11)$ \\
\hline Kidney & 4 & $8.31^{*}(2.26-21.27)$ & 4 & $2.1(0.57-5.38)$ & 3 & $1.89(0.39-5.52)$ & 1 & $0.56(0.01-3.11)$ \\
\hline Cranial Nerves/Other Nervous System & 1 & $109.46^{*}(2.77-609.86)$ & 0 & $0(0-103.57)$ & 0 & $0(0-131.8)$ & 1 & $36.03(0.91-200.74)$ \\
\hline All Lymphatic and Hematopoietic Diseases & 7 & $4.03^{*}(1.62-8.31)$ & 25 & $3.66^{*}(2.37-5.41)$ & 15 & $2.64^{*}(1.47-4.35)$ & 28 & $4.40^{*}(2.92-6.36)$ \\
\hline Lymphoma & 3 & $3.45(0.71-10.07)$ & 19 & $5.53 *(3.33-8.64)$ & 10 & $3.48^{*}(1.67-6.4)$ & 23 & $7.21 *(4.57-10.82)$ \\
\hline Hodgkin's Lymphoma & 0 & $0(0-75.01)$ & 0 & $0(0-19.72)$ & 2 & $13.60^{*}(1.65-49.11)$ & 1 & $6.71(0.17-37.39)$ \\
\hline HL - Nodal & 0 & $0(0-77.88)$ & 0 & $0(0-20.49)$ & 2 & $14.15^{*}(1.71-51.13)$ & 1 & $6.99(0.18-38.92)$ \\
\hline Non-Hodgkin's Lymphoma & 3 & $3.65(0.75-10.68)$ & 19 & $5.85^{*}(3.52-9.14)$ & 8 & $2.93^{*}(1.27-5.78)$ & 22 & $7.24 * 4.5310 .95$ \\
\hline NHL - Nodal & 1 & $1.8(0.05-10.02)$ & 12 & $5.48^{*}(2.83-9.58)$ & 1 & $0.55(0.01-3.06)$ & 9 & $4.51^{*}(2.06-8.57)$ \\
\hline $\mathrm{NHL}$ - Extranodal & 2 & $7.53(0.91-27.22)$ & 7 & $6.61^{*}(2.66-13.63)$ & 7 & $7.70 *(3.09-15.86)$ & 13 & $12.43^{*}(6.62-21.26)$ \\
\hline Leukemia & 3 & $5.18^{*}(1.07-15.14)$ & 4 & $1.76(0.48-4.52)$ & 5 & $2.66(0.86-6.2)$ & 3 & $1.42(0.29-4.16)$ \\
\hline Non-Lymphocytic Leukemia & 1 & $3.43(0.09-19.08)$ & 3 & $2.63(0.54-7.68)$ & 3 & $3.18(0.66-9.31)$ & 2 & $1.91(0.23-6.91)$ \\
\hline Acute Non-Lymphocytic Leukemia & 1 & $5.39(0.14-30.02)$ & 3 & $4.13(0.85-12.06)$ & 2 & $3.29(0.4-11.9)$ & 1 & $1.46(0.04-8.13)$ \\
\hline Myeloid and Monocytic Leukemia & 1 & $4(0.1-22.28)$ & 3 & $3.06(0.63-8.94)$ & 3 & $3.67(0.76-10.71)$ & 2 & $2.17(0.26-7.85)$ \\
\hline Acute Myeloid Leukemia & 1 & $6.41(0.16-35.74)$ & 2 & $3.25(0.39-11.76)$ & 2 & $3.84(0.46-13.86)$ & 1 & $1.67(0.04-9.3)$ \\
\hline
\end{tabular}

CI Confidence interval; $E$ Expected; HL Hodgkin's lymphoma; NHL Non-Hodgkin's lymphoma; O Observed; OAL Ocular adnexal lymphoma; SIR Standardized incidence ratio; SPM Second primary malignancy. ${ }^{*} P<0.05$ 
Table 4 Standardized incidence ratios and excess absolute risks of secondary malignancy distributed by age of patient

\begin{tabular}{|c|c|c|c|c|c|c|c|c|c|}
\hline \multirow[t]{3}{*}{ Cancer Site } & \multicolumn{9}{|c|}{ Age at Diagnosis of Ocular Adnexal Lymphoma } \\
\hline & \multicolumn{3}{|c|}{$0-49$ years old } & \multicolumn{3}{|c|}{$50-69$ years old } & \multicolumn{3}{|c|}{$70+$ years old } \\
\hline & 0 & O/E (95\% Cl) & $\mathrm{EAR}^{* *}$ & 0 & O/E (95\% Cl) & $\mathrm{EAR}^{* *}$ & 0 & O/E (95\% Cl) & $\mathrm{EAR}^{* *}$ \\
\hline All Sites & 12 & $2.41^{*}(1.25-4.22)$ & 28.77 & 99 & $1.33^{*}(1.08-1.62)$ & 38.98 & 168 & $1.1(0.94-1.28)$ & 23.15 \\
\hline Other Non-Epithelial Skin & 0 & $0(0-148.47)$ & -0.1 & 2 & $10.20^{*}(1.23-36.83)$ & 2.83 & 3 & $3.76(0.78-11)$ & 3.31 \\
\hline Female Breast & 2 & $1.49(0.18-5.37)$ & 2.68 & 6 & $0.53(0.19-1.15)$ & -8.45 & 11 & $0.61(0.31-1.1)$ & -10.4 \\
\hline Kidney & 2 & $12.77^{*}(1.55-46.12)$ & 7.55 & 5 & $2.32(0.75-5.41)$ & 4.47 & 5 & $1.45(0.47-3.38)$ & 2.33 \\
\hline Cranial Nerves/Other Nervous System & 0 & $0(0-453.34)$ & -0.03 & 1 & $26.25(0.66-146.24)$ & 1.51 & 1 & $18.43(0.47-102.69)$ & 1.42 \\
\hline All Lymphatic and Hematopoietic Diseases & 3 & $6.24 *(1.29-18.23)$ & 10.31 & 29 & $5.24^{*}(3.51-7.52)$ & 36.86 & 43 & $2.95^{*}(2.13-3.97)$ & 42.69 \\
\hline Lymphoma & 3 & $9.53^{*}(1.97-27.86)$ & 10.99 & 25 & $8.60^{*}(5.56-12.69)$ & 34.71 & 27 & $3.78^{*}(2.49-5.5)$ & 29.84 \\
\hline Hodgkin's Lymphoma & 1 & $13.34(0.34-74.35)$ & 3.79 & 2 & $10.93^{*}(1.32-39.49)$ & 3.85 & 0 & $0(0-13.44)$ & -0.41 \\
\hline HL - Nodal & 1 & $13.72(0.35-76.42)$ & 3.79 & 2 & $11.32^{*}(1.37-40.89)$ & 2.86 & 0 & $0(0-14.06)$ & -0.39 \\
\hline Non-Hodgkin's Lymphoma & 2 & $8.34^{*}(1.01-30.14)$ & 7.21 & 23 & $8.44^{*}(5.35-12.67)$ & 31.85 & 27 & $3.93^{*}(2.59-5.72)$ & 30.25 \\
\hline NHL - Nodal & 0 & $0(0-23.93)$ & -0.63 & 8 & $4.33^{*}(1.87-8.53)$ & 9.66 & 15 & $3.29^{*}(1.84-5.43)$ & 15.7 \\
\hline $\mathrm{NHL}$ - Extranodal & 2 & $23.37^{*}(2.83-84.42)$ & 7.84 & 15 & $17.12^{*}(9.58-28.24)$ & 22.19 & 12 & $5.18^{*}(2.68-9.05)$ & 14.55 \\
\hline Leukemia & 0 & $0(0-29.44)$ & -0.51 & 2 & $1.19(0.14-4.31)$ & 0.51 & 13 & $2.58^{*}(1.38-4.42)$ & 11.98 \\
\hline Non-Lymphocytic Leukemia & 0 & $0(0-48.13)$ & -0.31 & 1 & $1.31(0.03-7.3)$ & 0.37 & 8 & $3.10^{*}(1.34-6.11)$ & 8.14 \\
\hline Acute Non-Lymphocytic Leukemia & 0 & $0(0-79.16)$ & -0.19 & 1 & $1.99(0.05-11.08)$ & 0.78 & 6 & $3.62^{*}(1.33-7.89)$ & 6.53 \\
\hline Myeloid and Monocytic Leukemia & 0 & $0(0-51.61)$ & -0.29 & 1 & $1.44(0.04-8.01)$ & 0.48 & 8 & $3.63^{*}(1.57-7.16)$ & -0.17 \\
\hline Acute Myeloid Leukemia & 0 & $0(0-89.14)$ & -0.17 & 1 & $2.25(0.06-12.56)$ & 8.71 & 5 & $3.56^{*}(1.15-8.3)$ & 0.87 \\
\hline
\end{tabular}

CI Confidence interval; EAR Excess absolute risk; $E$ Expected; HL Hodgkin's lymphoma; NHL Non-Hodgkin's lymphoma; O Observed; OAL Ocular adnexal lymphoma; SIR Standardized incidence ratio; SPM Second primary malignancy. ${ }^{*}$ Per 10,000 individuals. ${ }^{*} P<0.05$

does not formally report recurrences, and a second primary tumor with the same histology would more likely represent a recurrence rather than a true SPM, especially in the case of lymphoproliferative disease. This finding is less likely due to synchronous or multicentric lymphoma, as increased incidence of NHL was found specifically following greater than 1-year latency periods. In contrast, HL demonstrated a unique latency period of 5-10 years between the time of primary OAL diagnosis and the SPM diagnosis, which may be due to potentially similar pathology and shared dysfunction of the lymphatic system; this finding was not specifically associated with any of the common OAL subtypes included in the sub-analysis, and may be associated with rarer OAL variants. Leukemia demonstrated increased incidence within a year from OAL diagnosis. This may be a result of increased cancer surveillance during the treatment and follow-up period immediately following cancer diagnosis leading to increased detection rather than a true increased incidence. On the contrary, studies $[16,17]$ examining NHL of non-specified sites also observed increased incidence of second primary leukemia, suggesting the validity of this finding which may be a result of shared pathophysiology or represent a transformation. Indeed, the most common OAL subtype associated with this finding was CLL/SLL, a tumor well-known for its proclivity to transform [18].
Shared risk factors, including genetic predisposition, or adverse long-term treatment effects may explain increased incidence of SPMs in certain sites [19]. The increased incidence of non-melanoma skin malignancies may be due to mutual risk factors such as UV exposure, $[20,21]$ whereas the increased incidence of SPMs of the kidney may be explained due to risk factors such as smoking, $[22,23]$ both of which are risk factors associated with NHL in general. SPMs of the skin did not demonstrate significant increase in incidence within any particular latency periods in this study. Conversely, SPMs of the kidney and nervous system (excluding the brain) exhibited significantly increased incidence within the first year following diagnosis of OAL. As with leukemia, this may result from detection bias rather than true increased incidence. Previous studies of NHL of non-specified sites did however report an increased incidence of secondary malignancies of these sites, signifying that these may indeed be true associations [16, 17].

We also demonstrated differences in SPM incidence based on patient age. It is important to note that SPMs of the kidney, non-epithelial skin, and HL were significantly increased in their respective age groups with an observed count of 2 malignancies each; clinical significance of these findings is indeterminate given the small numbers and that these malignancies could have arisen serendipitously. Other studies are necessary to validate 
Table 5 Site-specific standardized incidence ratios of SPMs in patients with varying prior OAL subtypes

\begin{tabular}{|c|c|c|c|c|c|c|c|c|c|c|}
\hline \multirow[b]{2}{*}{ Second Cancer Site } & \multicolumn{2}{|r|}{ EZML } & \multicolumn{2}{|r|}{$\mathrm{FL}$} & \multicolumn{2}{|r|}{ CLL/SLL } & \multicolumn{2}{|r|}{ DLBCL } & \multicolumn{2}{|r|}{ MCL } \\
\hline & 0 & SIR $(95 \% \mathrm{Cl})$ & 0 & O/E (95\%Cl) & 0 & O/E (95\%Cl) & 0 & O/E (95\%Cl) & 0 & O/E $(95 \% \mathrm{Cl})$ \\
\hline All Sites & 75 & $1.13(0.89-1.41)$ & 41 & $1.48 *(1.06-2.01)$ & 52 & $1.52^{*}(1.13-1.99)$ & 28 & $1.38(0.92-1.99)$ & 12 & $\begin{array}{l}1.2(0.62- \\
2.09)\end{array}$ \\
\hline $\begin{array}{l}\text { All Sites excluding Non-Melanoma } \\
\text { Skin }\end{array}$ & 74 & $1.12(0.88-1.4)$ & 40 & $1.45^{*}(1.04-1.97)$ & 52 & $1.52^{*}(1.14-2)$ & 28 & $1.38(0.92-2)$ & 11 & $\begin{array}{l}1.1(0.55- \\
1.97)\end{array}$ \\
\hline Colon, Rectum and Anus & 5 & $0.71(0.23-1.65)$ & 2 & $0.6(0.07-2.15)$ & 4 & $0.88(0.24-2.25)$ & 7 & $2.73^{*}(1.1-5.63)$ & 1 & $\begin{array}{l}0.84(0.02- \\
4.68)\end{array}$ \\
\hline Respiratory System & 6 & $0.58(0.21-1.27)$ & 5 & $1.12(0.36-2.61)$ & 11 & $2.02^{*}(1.01-3.62)$ & 0 & $0(0-1.15)$ & 3 & $\begin{array}{l}1.85(0.38- \\
5.41)\end{array}$ \\
\hline Female Breast & 5 & $0.54(0.18-1.26)$ & 3 & $0.81(0.17-2.37)$ & 0 & $0.00^{*}(0-0.75)$ & 5 & $1.73(0.56-4.04)$ & 1 & $\begin{array}{l}1.02(0.03- \\
5.7)\end{array}$ \\
\hline Kidney & 5 & $2.7(0.88-6.3)$ & 0 & $0(0-5.41)$ & 2 & $2.72(0.33-9.81)$ & 3 & $\begin{array}{l}6.28^{*}(1.3- \\
18.37)\end{array}$ & 1 & $\begin{array}{l}3.87(0.1- \\
21.55)\end{array}$ \\
\hline Cranial Nerves Other Nervous System & 0 & $0(0-125.28)$ & 1 & $\begin{array}{l}87.65^{*}(2.22- \\
488.37)\end{array}$ & 1 & $\begin{array}{l}68.95^{*}(1.75- \\
384.18)\end{array}$ & 0 & $0(0-418.03)$ & 0 & $0(0-857.12)$ \\
\hline Thyroid & 2 & $2.01(0.24-7.25)$ & 1 & $3.77(0.1-21.02)$ & 0 & $0(0-12.59)$ & 2 & $\begin{array}{l}9.64^{*}(1.17- \\
34.84)\end{array}$ & 0 & $0(0-43.31)$ \\
\hline $\begin{array}{l}\text { All Lymphatic and Hematopoietic } \\
\text { Diseases }\end{array}$ & 19 & $3.10^{*}(1.87-4.85)$ & 14 & $5.62 *(3.07-9.43)$ & 19 & $6.58^{*}(3.96-10.27)$ & 4 & $2.16(0.59-5.53)$ & 0 & $0(0-4.17)$ \\
\hline Non-Hodgkin Lymphoma & 14 & $4.75^{*}(2.59-7.96)$ & 9 & $7.51^{*}(3.43-14.25)$ & 12 & $8.73^{*}(4.51-15.25)$ & 2 & $2.27(0.27-8.2)$ & 0 & $0(0-9.03)$ \\
\hline NHL - Nodal & 9 & $4.69^{*}(2.15-8.91)$ & 3 & $3.73(0.77-10.9)$ & 2 & $2.13(0.26-7.68)$ & 2 & $3.4(0.41-12.29)$ & 0 & $0(0-13.47)$ \\
\hline $\mathrm{NHL}$ - Extranodal & 5 & $4.84^{*}(1.57-11.3)$ & 6 & $\begin{array}{l}15.21^{*}(5.58- \\
33.12)\end{array}$ & 10 & $\begin{array}{l}23.03^{*}(11.04- \\
42.36)\end{array}$ & 0 & $0(0-12.59)$ & 0 & $0(0-27.36)$ \\
\hline Leukemia & 5 & $2.54(0.82-5.93)$ & 3 & $3.59(0.74-10.48)$ & 5 & $5.14^{*}(1.67-12)$ & 1 & $1.59(0.04-8.88)$ & 0 & $0(0-12.44)$ \\
\hline $\begin{array}{l}\text { Acute Non-Lymphocytic Leukemia } \\
\text { (ANLL) }\end{array}$ & 2 & $3.09(0.37-11.17)$ & 1 & $3.79(0.1-21.1)$ & 3 & $9.57^{*}(1.97-27.98)$ & 1 & $\begin{array}{l}4.99(0.13- \\
27.79)\end{array}$ & 0 & $0(0-38.77)$ \\
\hline Acute Myeloid Leukemia & 1 & $1.74(0.04-9.68)$ & 1 & $4.43(0.11-24.67)$ & 3 & $\begin{array}{l}11.60^{*}(2.39- \\
33.91)\end{array}$ & 1 & $\begin{array}{l}5.87(0.15- \\
32.72)\end{array}$ & 0 & $0(0-45.66)$ \\
\hline Acute Monocytic Leukemia & 1 & $\begin{array}{l}35.06(0.89- \\
195.36)\end{array}$ & 0 & $0(0-296.17)$ & 0 & $0(0-237.19)$ & 0 & $0(0-386.43)$ & 0 & $0(0-803.64)$ \\
\hline Chronic Myeloid Leukemia & 1 & $4.01(0.1-22.34)$ & 0 & $0(0-35.16)$ & 0 & $0(0-29.13)$ & 0 & $0(0-45.86)$ & 0 & $0(0-97.75)$ \\
\hline Other Myeloid/Monocytic Leukemia & 0 & $0(0-158.88)$ & 1 & $\begin{array}{l}81.67^{*}(2.07- \\
455.04)\end{array}$ & 0 & $0(0-223.64)$ & 0 & $0(0-372.52)$ & 0 & $0(0-810.25)$ \\
\hline
\end{tabular}

Cl Confidence interval; CLL/SLL Chronic lymphocytic leukemia/small lymphocytic lymphoma; DLBCL Diffuse large B cell lymphoma; $E$ Expected; EMZL Extranodal marginal-zone B cell lymphoma; FL Follicular lymphoma; MCL Mantle cell lymphoma; O Observed; OAL Ocular adnexal lymphoma; SIR Standardized incidence ratio; SPM Second primary malignancy. ${ }^{*} P<0.05$

these findings or increase their power through metaanalysis. While age-related cancer screenings do not presently exist for these malignancy types, the clinician should be aware of these potential associations.

Interestingly, there was a reduced incidence of breast cancer SPMs compared to the general population, with particular latency in the one to ten-year period following OAL diagnosis. Prior studies assessing sequence of diagnosis in patients with both breast cancer and NHL suggest that breast cancer is more frequently diagnosed simultaneously or prior to the diagnosis of NHL [24]. Because the objective of our study is to determine subsequent malignancies, our inclusion criteria is limited to only first primary OAL and therefore does not examine cases of breast cancer that predate an OAL diagnosis. Similarly, our analysis does not assess simultaneously diagnosed malignancies (within $0-2$ months). It is therefore possible that this finding is reflective of such a unidirectional and sequential phenomenon rather than suggestive of an actual lower risk of breast cancer.

Additionally, there was no significant difference in incidence of non-lymphohematopoietic SPMs in the eye and orbit between patients with history of OAL and the reference population. This is consistent with what others have reported, and may be explained by inherent histopathological differences; lymphoma is distinct in histology from other types of ocular and periocular malignancies such as melanoma [16, 17]. Importantly, 
the absence of SPMs in this region suggests that treatment (e.g., radiation) is an uncommon cause of SPMs in patients with prior OAL.

Many second malignancy associations reported in studies examining NHL of any site were not observed in our study focusing solely on OAL. For example, Chattopadhyay, et al. have shown an increased risk for SPMs of the upper aerodigestive tract, gastrointestinal tract, lung, urinary bladder, melanoma, and thyroid gland [16]. Additionally, Chien and colleagues have found an increased incidence for SPMs of the stomach, head and neck, bone and soft tissue, thyroid, liver and biliary tract, and mediastinum [17]. The increased incidence of non-ocular mucosal malignancies in these studies may in part be explained due to our study including lymphomas solely of the ocular adnexa, whereas other studies included other primary sites of NHL such as the gastrointestinal tract. Extranodal lymphoma may originate from these nonocular mucosal sites and require treatment, such as with radiation, which may predispose these patients to future increased risks of SPMs in these non-ocular mucosal sites. In comparison, OAL is remotely located and is less likely to possess treatment-related predisposition of SPMs in these regions. Alternatively, differences in our findings may be explained by differing distributions of NHL subtypes in the ocular adnexa compared to NHL in general; for example, whereas DLBCL constitutes 9$13 \%$ of OAL, it is the most common subtype of NHL in general $(25-30 \%)[6,7,25]$. Our sub-analysis demonstrated that patients with DLBCL of the ocular adnexa had increased incidence of colorectal and thyroid malignancies. Because DLBCL comprises a minor proportion of OAL, its relative effect may be masked by the other lymphoma subtypes that more commonly originate from the ocular adnexa and possess no relative difference in risk of colorectal or thyroid malignancies.

Although it has previously been documented that second primary malignancies following NHL do not differ by subtype, we found great variation of both overall and site-specific SPM risks between OAL subtypes in our sub-analysis [26]. Although this sub-analysis of SPM risk associated with specific OAL subtypes may prove helpful in explaining our overall findings, it must be interpreted with great caution, as sample sizes may represent as little as $3.8 \%(69 / 1834)$ of the overall cohort such as in the case of MCL. Future studies with larger sample size are necessary to reliably determine SPM risk associated with specific OAL subtypes.

The main limitations of this study, which utilizes the SEER cancer database, are its retrospective design and the inherent flaws associated with public databases. Our finding of overall increased risk of malignancies may be falsely elevated due to inclusion of likely misclassified NHL recurrences (18.6\%; 52/279). The MP-SIR algorithm is unable to calculate SPMs without inclusion of all malignancies, limiting our ability to account for this confounding factor. Nonetheless, findings related to other site specific SPMs are highly reliable and of important clinical value. Additional issues include possible miscoding, underreporting (e.g., surgical treatment type), lack of variables related to radiation (e.g., dose, field, sessions), and unreliable or missing information regarding size and stage (e.g. 1834/1834 unknown Ann Arbor stage). Furthermore, limitations in reporting of chemotherapy (yes, no/unknown) and radiation (yes, no/unknown) data hinder our ability to explore treatment related effects. Risk of malignancy is affected by lifestylerelated factors such as smoking [22, 23, 27]. These factors are not recorded in SEER and would have strengthened our study if adjusted for. Additionally, patients may move from one region of the country to another and receive diagnosis and treatment for a SPM at a facility that does not report data to SEER. Therefore, our results may reflect overall underreporting in this regard, and there may be other types of SPM in patients with primary OAL that were not identified here. It is also possible that patients with less advanced disease are underrepresented, as ophthalmologists may be more comfortable treating these patients alone, without consultation from an oncologist or cancer center that collaborates with SEER; there is a lack of consensus, however, on how advanced initial disease impacts risk of SPMs, with early stage patients generally having longer survival periods in which they may develop SPMs and advanced stage patients receiving treatment that may elevates their risk for particular SPMs [28, 29]. Improved treatment options for lymphoma in the modern era have led to decreased SPMs that may affect outcomes in our study which encompasses cases diagnosed between 1973 and 2015 [30]. Despite these limitations, the SEER database has been validated for such analyses [31, 32].

\section{Conclusion}

Our findings suggest that there is an increased risk of SPMs in patients with primary OAL, both of the lymphoreticular system and amongst solid sites. SPM risk may vary by OAL subtype. Patients with primary OAL may benefit from providers' increased awareness of these risks. While additional investigation is needed, it may be prudent for healthcare providers (e.g., primary care, oncology, ophthalmology) of patients with prior OAL to monitor for high-risk SPMs during follow-up. Interdisciplinary coordination of care for each patient may facilitate early diagnosis and treatment, potentially improving long-term outcomes.

\section{Abbreviations}

Cl: Confidence interval; CLL/SLL: Chronic lymphocytic leukemia/small lymphocytic lymphoma; DLBCL: Diffuse large B-cell lymphoma; EAR: Excess 
absolute risk; E: Expected; EMZL: Extranodal marginal-zone B-cell lymphoma; FL: Follicular lymphoma; HL: Hodgkin's lymphoma; MCL: Mantle cell lymphoma; NCl: National cancer institute; NHL: Non-Hodgkin's lymphoma; NOS: Not otherwise specified; O: Observed; OAL: Ocular adnexal lymphoma; MP-SIR: Multiple primary standardized incidence ratio; SEER: Surveillance, epidemiology, and end results; SIR: Standardized incidence ratio; SPM: Second primary malignancy

\section{Acknowledgements}

Not applicable.

\section{Authors' contributions}

$A L, V R, T A$, and CYW had full access to all of the data in the study and take responsibility for the integrity of the data and the accuracy of the data analysis. AL, VR, TA, CYW all contributed to study design, interpretation of data, drafting of the manuscript, and critical revision of the manuscript. AL and TA completed the statistical analysis. All authors have reviewed and approved the final manuscript.

\section{Funding}

No funding was acquired for this study.

\section{Availability of data and materials}

The data that support the findings of this study are made available by National Cancer Institute's Surveillance, Epidemiology, and End Results Program (SEER). Data can be obtained from SEER upon completing their agreement form and requesting access from their website (https://seer. cancer.gov). The specific dataset utilized was "SEER 9 Regs Research Data, Nov 2017 Sub (1973-2015)."

\section{Declarations}

\section{Ethics approval and consent to participate}

No institutional review board approval was required for this study, as only deidentified data obtained with permission from $\mathrm{NCl}$ was analyzed. The submission does not meet the definition of "human subject research" as defined by the regulations 45 CFR46.102 (e); data was neither obtained via intervention/interaction with a living individual by the investigator, nor was identifiable.

\section{Consent for publication}

Not applicable.

\section{Competing interests}

The authors declare that they have no competing interests. CYW is a consultant to Allergan/AbbVie, Inc.; Alcon, Inc.; Alimera Sciences, Inc.; Regeneron; REGENXBIO; Genentech; Novartis; Dutch Ophthalmic Research Center.

\section{Author details}

'Baylor College of Medicine, School of Medicine, 1 Baylor Plaza, Houston, TX 77030, USA. ${ }^{2}$ University of Texas Medical Branch at Galveston, School of Medicine, 301 University Blvd., Galveston, TX 77555, USA. ${ }^{3}$ Baylor College of Medicine, Department of Ophthalmology-Cullen Eye Institute, 1977 Butler Boulevard, Houston, TX 77030, USA.

\section{Received: 18 April 2020 Accepted: 25 March 2021} Published online: 07 April 2021

\section{References}

1. Feinstein AR, Krause AC. Ocular involvement in lymphomatous disease. AMA Arch Ophthalmol. 1952:48(3):328-37 [cited 2018 Oct 28] Available from: http://www.ncbi.nlm.nih.gov/pubmed/14952095.

2. Demirci H, Shields CL, Shields JA, Honavar SG, Mercado GJ, Tovilla JC. Orbital tumors in the older adult population. Ophthalmology. 2002;109(2): 243-8 [cited 2018 Oct 28] Available from: http://www.ncbi.nlm.nih.gov/ pubmed/11825802.

3. Coupland SE, Krause L, Delecluse H-J, Anagnostopoulos I, Foss H-D, Hummel $\mathrm{M}$, et al. Lymphoproliferative lesions of the ocular adnexa. Ophthalmology. 1998;105(8):1430-41 [cited 2018 Oct 28] Available from: http://www.ncbi.nlm.nih.gov/pubmed/9709754.
4. Krol ADG, le Cessie S, Snijder S, Kluin-Nelemans JC, Kluin PM, Noordijk EM. Primary extranodal non-Hodgkin's lymphoma (NHL): the impact of alternative definitions tested in the comprehensive cancer centre west population-based NHL registry. Ann Oncol Off J Eur Soc Med Oncol. 2003; 14(1):131-9 [cited 2018 Oct 29] Available from: http://www.ncbi.nlm.nih. gov/pubmed/12488305.

5. Swerdlow SH, Campo E, Harris NL, Jaffe ES, Pileri SA, Stein H. WHO classification of tumours of haematopoietic and lymphoid tissues, 4th ed. Lyon: IARC; 2008. p. 585. [cited 2018 Oct 29]. Available from: https://publica tions.iarc.fr/Book-And-Report-Series/Who-Classification-Of-Tumours/WHO-Cla ssification-Of-Tumours-Of-Haematopoietic-And-Lymphoid-Tissues-2017.

6. Holm F, Mikkelsen LH, Kamper P, Rasmussen PK, Larsen TS, Sjö LD, et al. Ocular adnexal lymphoma in Denmark: a nationwide study of 387 cases from 1980 to 2017. Br J Ophthalmol. 2020 ; ;bjophthalmol-2019-315637. [cited 2020 Nov 7] Available from: https://bjo.bmj.com/lookup/doi/https:// doi.org/10.1136/bjophthalmol-2019-315637

7. Ferry JA, Fung CY, Zukerberg L, Lucarelli MJ, Hasserjian RP, Preffer Fl, et al. Lymphoma of the ocular adnexa: a study of 353 cases. Am J Surg Pathol. 2007;31(2):170-84 [cited 2020 Nov 7] Available from: http://journals.Iww. com/00000478-200702000-00002.

8. Travis LB. The epidemiology of second primary cancers. Cancer Epidemiol Biomarkers Prev. 2006;15(11):2020-6 [cited 2018 Oct 28] Available from: http://www.ncbi.nlm.nih.gov/pubmed/17057028.

9. $\mathrm{Ng} J$, Shuryak I. Minimizing second cancer risk following radiotherapy: current perspectives. Cancer Manag Res. 2015;7:1-11 [cited 2018 Oct 29] Available from: http://www.ncbi.nlm.nih.gov/pubmed/25565886.

10. Decaudin D, de Cremoux P, Vincent-Salomon A, Dendale R, Rouic LL-L. Ocular adnexal lymphoma: a review of clinicopathologic features and treatment options. Blood. 2006;108(5):1451-60 [cited 2018 Oct 28] Available from: http://www.ncbi.nlm.nih.gov/pubmed/9473230.

11. Vasudevan V, Cheung MC, Yang R, Zhuge Y, Fischer AC, Koniaris LG, et al. Pediatric solid tumors and second malignancies: characteristics and survival outcomes. J Surg Res. 2010;160(2):184-9 [cited 2019 mar 14] Available from: http://www.ncbi.nlm.nih.gov/pubmed/19765728.

12. Abdulwahab A, Sykes J, Kamel-Reid S, Chang H, Brandwein JM. Therapyrelated acute lymphoblastic leukemia is more frequent than previously recognized and has a poor prognosis. Cancer. 2012;1 18(16):3962-3967. [cited 2019 Mar 14] Available from: http://doi.wiley.com/https:/doi.org/10.1 002/cncr.26735

13. Tamboli D, Topham A, Singh N, Singh AD. Retinoblastoma: a SEER dataset evaluation for treatment patterns, survival, and second malignant neoplasms. Am J Ophthalmol. 2015;160(5):953-8 [cited 2018 Oct 29] Available from: http://www.ncbi.nlm.nih.gov/pubmed/26255575.

14. Laíns I, Bartosch C, Mondim V, Healy B, Kim IK, Husain D, et al. Second primary neoplasms in patients with uveal melanoma: a SEER database analysis. Am J Ophthalmol. 2016;165:54-64 [cited 2018 Oct 29] Available from: http://www.ncbi.nlm.nih.gov/pubmed/26940164.

15. Surveillance, Epidemiology, and End Results (SEER) Program (www.seer.ca ncer.gov) SEER*Stat Database: Incidence - SEER 9 Regs Research Data (with additional treatment fields), Nov 2017 Sub (1973-2015) - Linked To County Attributes - Total U.S., 1969-2016 Counties, National Cancer Institute, DCCP S, Surveillance Research Program, released April 2018, based on the November 2017 submission.

16. Chattopadhyay S, Sud A, Zheng G, Yu H, Sundquist K, Sundquist J, et al. Second primary cancers in non-Hodgkin lymphoma: Bidirectional analyses suggesting role for immune dysfunction. Int J Cancer. 2018;143(10):24492457. [cited 2019 Mar 13] Available from: http://doi.wiley.com/https://doi. org/10.1002/ijc.31801

17. Chien S-H, Liu C-J, Hong Y-C, Teng C-J, Hu Y-W, Ku F-C, et al. Development of second primary malignancy in patients with non-Hodgkin lymphoma: a nationwide population-based study. J Cancer Res Clin Oncol. 2015;141(11): 1995-2004. [cited 2019 mar 13]. Available from: http://www.ncbi.nlm.nih. gov/pubmed/25971624.

18. Agbay RLMC, Jain N, Loghavi S, Medeiros LJ, Khoury JD. Histologic transformation of chronic lymphocytic leukemia/small lymphocytic Iymphoma. Am J Hematol. 2016;91(10):1036-1043. [cited 2020 Nov 7] Available from: http://doi.wiley.com/https://doi.org/10.1002/ajh.24473

19. Brennan P, Scélo G, Hemminki K, Mellemkjaer L, Tracey E, Andersen A, et al. Second primary cancers among 109000 cases of non-Hodgkin's lymphoma. Br J Cancer. 2005;93(1):159-66 [cited 2019 mar 28] Available from: http:// www.ncbi.nlm.nih.gov/pubmed/15970927. 
20. McMichael AJ, Giles GG. Have increases in solar ultraviolet exposure contributed to the rise in incidence of non-Hodgkin's lymphoma? $\mathrm{Br}$ Cancer. 1996;73(7):945-50 [cited 2019 Mar 13]; Available from: http://www. ncbi.nlm.nih.gov/pubmed/8611412.

21. Cartwright R, McNally R, Staines A. The increasing incidence of NonHodgkin's Lymphoma (NHL): the possible role of sunlight. Leuk Lymphoma. 1994;14(5-6):387-94 [cited 2019 Mar 13] Available from: http://www.ncbi. nlm.nih.gov/pubmed/7812197.

22. Chow W-H, Dong LM, Devesa SS. Epidemiology and risk factors for kidney cancer. Nat Rev Urol. 2010;7(5):245-57 [cited 2019 mar 13] Available from: http://www.ncbi.nlm.nih.gov/pubmed/20448658

23. Stagnaro E, Tumino R, Parodi S, Crosignani P, Fontana A, Masala G, et al. Non-Hodgkin's lymphoma and type of tobacco smoke. Cancer Epidemiol Biomarkers Prev. 2004;13(3):431-7 [cited 2019 mar 13] Available from: http:// www.ncbi.nlm.nih.gov/pubmed/15006920.

24. Wiernik PH, Hu X, Ratech H, Fineberg S, Marino P, Schleider MA, et al. NonHodgkin's lymphoma in women with breast cancer. Cancer J. 6(5):336-42 [cited 2019 Nov 13] Available from: http://www.ncbi.n/m.nih.gov/ pubmed/11079174.

25. Chihara D, Nastoupil $\sqcup$, Williams JN, Lee P, Koff JL, Flowers CR. New insights into the epidemiology of non-Hodgkin lymphoma and implications for therapy. Expert Rev Anticancer Ther. 2015;15(5):531-44. [cited 2020 Nov 7]. Available from: /pmc/articles/PMC4698971/?report=abstract. https://www.ta ndfonline.com/toc/iery20/current.

26. Rossi C, Jégu J, Mounier M, Dandoit M, Colonna M, Daubisse-Marliac L, et al. Risk assessment of second primary cancer according to histological subtype of non-Hodgkin lymphoma. Leuk Lymphoma. 2015;56(10):2876-2882. [cited 2019 Mar 13] Available from: http://www.tandfonline.com/doi/full/https:// doi.org/10.3109/10428194.2015.1007505

27. Lutz JM, Cree IA, Foss AJ. Risk factors for intraocular melanoma and occupational exposure. Br J Ophthalmol. 1999:83(10):1190-3 [cited 2019 mar 13] Available from: http://www.ncbi.nlm.nih.gov/pubmed/10502585.

28. Amer MH. Multiple neoplasms, single primaries, and patient survival. Cancer Manag Res. 2014;6(1):119-34.

29. Major A, Smith DE, Ghosh D, Rabinovitch R, Kamdar M. Risk and subtypes of secondary primary malignancies in diffuse large B-cell lymphoma survivors change over time based on stage at diagnosis. Cancer. 2020;126(1):189-201 [cited 2020 Mar 28] Available from: http://www.ncbi.nlm.nih.gov/ pubmed/31509235.

30. Lemieux MH, Solanki AA, Mahmood U, Chmura SJ, Koshy M. Risk of second malignancies in patients with early-stage classical Hodgkin's lymphoma treated in a modern era. Cancer Med. 2015;(4):513-8 [cited 2019 Mar 13] Available from: https://www.ncbi.nlm.nih.gov/pmc/articles/PMC4402065/ pdf/cam40004-0513.pdf.

31. Singh AD, Turell ME, Topham AK. Uveal melanoma: trends in incidence, treatment, and survival. Ophthalmology. 2011;118(9):1881-5 [cited 2019 Mar 13] Available from: https://www.sciencedirect.com/science/article/pii/S0161 64201100073X.

32. Inskip PD. Multiple primary tumors involving cancer of the brain and central nervous system as the first or subsequent cancer. Cancer. 2003;98(3):562570. Available from: http://doi.wiley.com/https://doi.org/10.1002/cncr.11554

\section{Publisher's Note}

Springer Nature remains neutral with regard to jurisdictional claims in published maps and institutional affiliations.

Ready to submit your research? Choose BMC and benefit from:

- fast, convenient online submission

- thorough peer review by experienced researchers in your field

- rapid publication on acceptance

- support for research data, including large and complex data types

- gold Open Access which fosters wider collaboration and increased citations

- maximum visibility for your research: over $100 \mathrm{M}$ website views per year

At BMC, research is always in progress.

Learn more biomedcentral.com/submissions 